\title{
1. Competition law in flux: established and emerging approaches to methodology
}

\author{
Deborah Healey and Rhonda L. Smith
}

The dynamic environment of competition law has reverberated globally of late in unprecedented fashion. While the competition law environment has traditionally been one of change for reasons as diverse as differing legal systems, political economies and economic views, spectacular growth in the number of jurisdictions adopting competition laws, particularly since the new millennium, has emphasized just how many views there are on what constitutes an effective competition law, the methodology for its application and enforcement, and what other policies might support it. Coupled with the growth of the digital environment, which has thrown new challenges to the assessment of anticompetitive conduct, the competition law world is in a substantial state of re-examination and potential refinement. The extent to which major change is necessary is under consideration in many jurisdictions.

There is general agreement about the types of conduct which should be subject to competition law, but global convergence will not happen in the near future, if ever, despite attempts to do so. In any event, identical provisions in all countries would still lead to dissimilar approaches and outcomes due to cultural values, legal systemic issues, political elements, agency differences and market distinctions. ${ }^{1}$

This edited collection was assembled with the view that while certain basic economic concepts and anticompetitive conduct should be at the core of competition law, there were many approaches to the way they would be adopted in each jurisdiction, particularly in developing countries. The book gives due consideration to the more traditional approaches to competition law and respects the experience of the jurisdictions which have applied the law for many years. However, governments are assumed to seek the best competition outcomes for markets in their jurisdictions, with the qualification that exceptions and goals not related to competition are likely to dilute the benefits of competition in their markets which might otherwise be achieved. This book thus provides an overview of the competition law world at a time of substantial change.

\footnotetext{
1 A number of international agencies work to raise the standard of competition law implementation and enforcement, encouraging the development and convergence of methodology. The International Competition Network's mission is to 'advocate the adoption of superior standards and procedures in competition policy around the world, formulate proposals for procedural and substantive convergence, and seek to facilitate effective international cooperation to the benefit of member agencies, consumers and economies worldwide', https://www.internationalcompetitionnetwork.org/. The United Nations Commission for Trade and Development focuses on 'the creation of a safe, stable and attractive environment for enterprise and industry, through fair, sound and robust national competition', https://unctad.org/ en/Pages/DITC/CompetitionLaw/Competition-Law-and-Policy.aspx. The Organisation for Economic Co-operation and Development works to encourage 'well-designed competition law, effective enforcement and competition-based economic reform', https:/www.oecd.org/daf/competition/. Despite detailed and strategic work by these organizations, the task of convergence is very difficult.
} 
The chapters are analytical rather than descriptive, seeking to examine and assess the operation of competition laws, their methodologies and the issues faced, in a range of representational jurisdictions. The editors sought example jurisdictions from all continents in an attempt to globalize discussions around important ongoing issues.

In a more practical sense, this book examines competition law under three main themes or perspectives, which the contributors were asked to consider in a global context.

The first is the methodology of competition law: What does a competition law contain? What methods are used to apply the law within the jurisdiction? How are markets analysed? What are the accepted economic views on market competition and which economic approach is adopted? What other possible fields, such as empirical competition law or the sociology of competition law, does it consider in implementing and applying its competition law? What other factors are considered in its competition law determinations?

Second, the book asks how competition law is applied procedurally within a jurisdiction. Is there an administrative or court-based system of enforcement or a mix of the two? Are courts specialized or general in nature? How is the competition regulator constituted and funded? What is its degree of independence? How are fines and other remedies imposed and enforced? Is there a private right of action and can compensation or damages be recovered by injured parties?

Finally, the book has a comparative dimension. Some chapters provide internal comparison across jurisdictions, while others offer the opportunity for chapter-on-chapter comparison. Several chapters specifically compare aspects of the law and its enforcement in more than one jurisdiction, to give the flavour of the similarities and differences which exist even in jurisdictions which are closely linked politically or geographically. Each of the comparisons is both substantive, showing differences in the policy behind the individual competition laws, and procedural, showing differences in how the competition laws of jurisdictions apply and enforce the pillars of competition law: cartels and other horizontal and vertical arrangements; monopolies (or abuse of dominance); and mergers. The chapters seek to employ deep comparisons, although the capacity to do so necessarily varies with the length and depth of experience within a particular jurisdiction.

Some chapters focus on areas where a jurisdiction takes a particularly unusual approach to a competition problem, or where a comparison in a particular area might be useful as an exemplar for other jurisdictions.

Part I is entitled 'The objects and economics of competition law'. It contains this chapter, followed by chapters which set the goals, economic background and methodology of the substantive chapters which follow.

Chapter 2, 'The ambit of competition law: comments on its goals', is a detailed examination by Deborah Healey of current discussions surrounding the goals of competition law. It explores goals in the context of both 'traditional' models and templates, and the newer range of goals which have been adopted in developing jurisdictions and by more recent adopters of competition law. It examines these issues against the basic questions of why we have competition law and the methodology for its application. Individual goals and methodologies significantly impact the interpretation and application of competition laws and the discussion thus provides an important background to the book as a whole. The chapter charts these issues at a time when there are divergent views around what the goals should be, the effectiveness of existing models, and whether broader or multiple goals should be adopted or accepted as being effective. The analysis is pursued against the background of significant global developments, 
such as the perceived rise of market power in large corporations globally, the rise of digital platforms, and other market features such as the impact on privacy of these developments. Substantial consideration is also given to the goals of developing nations, particularly in Asia, and their distinctions as against more traditional templates, to show that a one-size-fits-all approach is not being taken.

The conclusion is that a number of divergent and distinct arguments are bundled into current debates. Most jurisdictions have the broad goal of fostering a strong and competitive environment, loosely for the benefit of consumers, whether this is stated expressly or is implied. Additional or alternative goals are deemed appropriate in many developing jurisdictions, but there is currently no template for them, nor particular means of determining priority between multiple goals in circumstances where they may conflict in their application or enforcement. The author is of the view that discussions about goals and application will certainly continue for some time and that younger jurisdictions may ultimately provide working examples of alternative goals to other jurisdictions, but not in the short term.

In purely economics-based Chapter 3, 'The cost of progress: hurdles facing antitrust's economic advance', Alan Devlin sets out a detailed analysis of the use of empiricism in competition law, focusing particularly on the US experience. The author argues that while the competitive implications of conduct are not always clear, purely doctrinal analysis should ebb as the body of useful empirical evidence grows. The decision by an enforcer in the US of whether to challenge a merger, for example, now invariably turns on data-driven analysis. As the author states, simulations based on willingness-to-pay scenarios can predict price effects; diversion ratios estimate substitutability; and gross upward pricing pressure indices measure a firm's post-merger incentive to raise price in a market for differentiated products. These approaches can bypass the traditional assessment of market definition and may obviate inferences about a firm's power to raise price from its share of a market. So, he concludes that the use of these econometric devices is generally to be applauded.

However, the author identifies at least three difficulties with these processes: first, he states that there is disparity between how regulators analyse the competitive effects of a merger when they intervene, and how they approach proof of these effects in their court proceedings. Second, the relegation of traditional doctrinal considerations such as market definition may undermine the consistency and predictability of competition law decision-making. Third, the author states that economic progress in antitrust has yielded a more refined enquiry focused on price, output and dynamic efficiency effects. This arguably narrows the remit of antitrust law, fostering industrial concentration and entrenchment of economic power. The chapter uses cases to explore these important methodological issues.

Chapter 4 by Geoff Edwards and Jennifer Fish is entitled 'The relevance of economics in US, EU and Australian competition law'. It considers in detail the use of economic analysis in competition law and policy in these jurisdictions, comparing the individual approaches to form-based and economic effects-based analyses in each. Through in-depth consideration of important case law, the authors review trends and show that while the US is firmly focused on effects-based thinking, the EU has until relatively recently remained a form-based system. They identify the substantial evolution in the EU since 2000 towards a more effects-based approach but illustrate some notable backtracking on occasion. Australia, by way of contrast, has shifted to a more effects-based analysis, but the authors note that form-based thinking is still apparent in that jurisdiction. They conclude, however, that the trend towards economic uniformity in these jurisdictions is threatened by the re-emergence of populist antitrust theo- 
ries based on ideas of bigness of large firms and concentration. These take a different approach to the current economic orthodoxy, particularly in the US.

While the earlier chapters focused primarily on use of economics in the US and the EU, a novel Chapter 5 by Lin Ping and Yan Yu, 'The use of economics in competition law enforcement in mainland China and Hong Kong', carefully evaluates the economic approach in these two important jurisdictions. It focuses on China, which implemented its Anti-Monopoly Law in 2008, and compares its approach with that of its 'one-country-two-systems' neighbour Hong Kong, a more recent adopter of competition law. The approach of China is critically important since it is now the third major regulator in terms of numbers of merger reviews, following the US and the EU. Many of these mergers are global transactions either involving a Chinese company or a foreign company operating in China, or with impact in China. This merger conduct and these merger reviews have the potential to impact commerce worldwide. Other anticompetitive conduct by Chinese and foreign firms in China also has the capacity to impact global trade. For these reasons, China has the capacity to be a particularly influential jurisdiction, so this chapter is of significance. The contrast with the more recent application of the competition law in Hong Kong and the approach of its regulators is significant.

The chapter compares the substantive provisions and the approach to enforcement and sanctions available under the two laws, before examining in depth the approach to economic methodology in the two jurisdictions. Guidelines issued by regulators are considered in assessing the substantive provisions and the methodologies for determining whether the laws have been breached. Important cases provide exemplars of economic methodology. Views on Hong Kong are substantially provided via the views of the regulator since there have been few cases to date. The authors conclude that China has shown strong willingness to use economic analysis in its competition law cases, mainly along international lines, and that the guidelines of the Hong Kong Competition Commission indicate that rigorous economic analysis in line with international standards will be employed in Hong Kong.

Part II of the book, 'The content of the law', is focused on the content of individual laws and the way in which the pillars of competition law are drafted and assessed in multiple jurisdictions.

Chapter 6, 'Cartel prohibition and the search for deterrent penalties: the United States, the European Union, Australia and China compared', by Mark Williams, surveys the very different cartel laws of these four jurisdictions in the context of analysing which model works best to successfully deter cartel conduct. The author concludes that despite improved detection techniques, increased fines and penalties, and the imposition of individual criminal liability, there appears to be little reduction in cartel activity. Detailed consideration is given to each law, addressing application, tests, enforcement mechanisms including leniency policies, and historical outcomes. Institutional and procedural issues are considered, as well as the impact of personal liability. Substantial comparisons are drawn and assessed. In conclusion, the author explains that the views of cartel cases within the four jurisdictions are basically similar, but differences reflect the 'idiosyncrasies of the legal order', differing drafting styles, and 'other environmental factors'. The chapter advocates for individual civil sanctions in the EU and China and recommends that Australia should make more use of its existing armoury of individual sanctions to improve outcomes and deterrence.

'Algorithm-driven collusive conduct' is the subject of Chapter 7 by Rob Nicholls. The chapter examines the extent to which anticompetitive conduct which is cartel-like may be facilitated by data-driven technologies, particularly facilitation arising from the use of algo- 
rithms. The author explains the implications in detail and in the context of important distinctions in the meaning of terms as between computer science, economics and competition law. He notes that even parallel conduct which might be facilitated by algorithms may result in collusion, particularly where the sector in question exhibits collusive oligopoly characteristics. Both horizontal and vertical price-fixing issues may be relevant, as well as hybrid collusion based on both vertical and horizontal conduct. These issues are important when one considers the increasing use of machine learning and artificial intelligence in businesses of many kinds. The chapter also addresses the issues which arise from the use of algorithm-based platform businesses. Finally, the chapter analyses the limits of the law in the US, the EU and Australia to deal with issues of this kind.

Chapter 8 by Miguel de la Mano and Alison Jones is entitled 'Vertical agreements under EU competition law: proposals for pushing Article 101 analysis, and the modernization process, to a logical conclusion'. The authors examine the analysis of vertical agreements in the EU in the context of modernization and the adoption of a more 'effects-based' approach based on a consumer welfare objective. They conclude that the current approach does not adequately reflect the economic logic of vertical restraints and relies heavily on presumptions of illegality. Distinctions in decision-making at a national level have not assisted the process and compound uncertainties. The chapter argues that change would be assisted by publication of carefully selected decisions and especially more complex effects cases, which would allow the EU courts to scrutinize the EC's policies in order to clarify and develop the law.

Chapter 9 by Rhonda Smith and Deborah Healey, 'Unilateral conduct analysis: focus on harm in multiple guises', reviews the law dealing with unilateral use of market power in multiple jurisdictions, focusing on the methodology employed to determine whether conduct is harmful to market competition. It addresses the US Chicago School approach to monopolization, with its more laissez-faire view of the issue and its consideration of whether conduct has a business rationale (which generally means that it is efficiency enhancing and not in breach of the law), and compares this with other approaches. In Europe and Asia, for example, there is more of a belief in fairness, which is reflected in the goals or policy objectives of the law, as noted in Chapter 2. This approach examines efficiency but is more sensitive to the fair distribution of wealth and recognizing incentives for innovation. Other jurisdictions, such as China, take a slightly different approach again.

The focus on market power is at the heart of issues of competition law but market power is a matter of degree and different jurisdictions set different thresholds for addressing the issue, as explained. The two models for enforcement, administrative or court-based decision-making, are identified and their advantages and disadvantages are discussed. Other differences discussed include the role of private versus public enforcement, and the severity of penalties for anticompetitive unilateral conduct, which in part reflect differing philosophies as to the role of penalties.

In the section dealing with methodology, the focus is on how differing jurisdictions assess market power - what indicators are used and which are rejected. While diminishing, there remains a striking difference between the economics-based approach in the US and the form-based approach of the EU, as discussed. Determining whether unilateral conduct is likely to be anticompetitive is prone to error, so tests have been developed to reduce this risk and the pros and cons of the various tests are discussed.

The chapter concludes with a discussion of the potential problems that arise in addressing anticompetitive unilateral conduct in the digital environment. Applying established approaches 
to market definition and the identification of market power will need to be modified if competition law enforcement is to be effective.

Chapter 10, by Rhonda Smith, concerns mergers. Mergers may have anticompetitive consequences either by increasing the ability to collude, including tacitly, and/or by conferring or increasing the unilateral market power of the merged entity. These economic effects are far reaching and are not easily redressed post merger, which explains why competition authorities are so concerned about them. The treatment of mergers in three jurisdictions - the US, the EU and Australia - is the focus of the chapter. The merger control process in the three jurisdictions is compared and discussed, as are the processes used to analyse the competition effects. Some brief conclusions about the treatment of mergers under competition law are drawn. Globalization of markets and technology that significantly reduces search costs mean that many mergers that may have raised competition concerns in the past will no longer do so. However, firms proposing multi-country mergers face significant costs associated with the differing requirements and approaches in those countries. A key problem for merger enforcement has always been that the effects of a merger will not be known until some time in the future. Predicting the future performance of smaller firms that are the takeover targets of the digital giants such as Google is an increasing problem for competition authorities, especially when these mergers are assessed by a court.

Chapter 11, 'Competition law in Japan, Malaysia and the Philippines: an overview', by Mel Marquis, provides a useful analysis of the laws of these three jurisdictions, one of which (Japan) is a long-standing competition law jurisdiction, while the others are younger jurisdictions. The author situates the three individual laws in their legal, institutional and cultural structures to identify issues which might impact the ability for competition law to effectively function. All three laws have as their aim the promotion and protection of competition, but the jurisdictions all see competition law as a means of encouraging economic development. Fairness is also a feature of the laws. The similarities and distinctions between the laws of the three jurisdictions are addressed in detail, highlighting the strengths and weaknesses of each law in contrast to the others. Each of the relevant pillars of the laws is discussed. Enforcement is surveyed from the angles of regulatory structure, procedure and effectiveness, as well as investigatory powers, enforcement history and levels of success. The guidelines of the individual regulators are noted. The chapter concludes that each jurisdiction has its own strengths and weaknesses.

Chapter 12, by Dragan Penezic and Zoran Soljaga, 'Building an efficient system of protection of competition in Serbia on its path to the EU', traverses the development of competition law in Serbia. The authors emphasize the importance of competition policy for the development of an efficient and competitive market economy, along with other policies such as foreign trade and investment, privatization, public procurement and general liberalization. They outline challenges to the introduction of competition policy in Serbia, such as state presence in the market, the low level of awareness of competition law and policy among relevant stakeholders, a regulatory regime which was not procompetitive, and support for national champions and state-owned enterprises. The EU and the process of EU integration were important features of the adoption of the law.

The chapter charts the introduction of the first competition law at the end of the 1990s, noting its strengths and weaknesses. The first 'modern' competition law was passed in 2005, but it was also found wanting. Finally, a new law was passed in 2009, and the authors explain this law in detail, noting its similarities with EU law and discussing its strengths and weak- 
nesses. The chapter also explains the institutional organization of the regulator, its competencies and processes for review, and its enforcement history. It makes a number of suggestions for its ongoing development.

Chapter 13 by Fernando Furlan, entitled 'Merger review updates in Latin America', provides a useful summary of recent changes to merger laws and merger review in Brazil, Chile and Mexico over the last few years. The author outlines the changes, noting that each jurisdiction has modified existing procedures based on experience and on international best practice. In each jurisdiction there has been strong political support which is essential to real success.

Part III of the book, 'Particular issues', contains chapters which address several aspects of competition law that are relatively unique exemplars for specific competition law problems, or which address unusual provisions within particular laws.

The first chapter in this part, Chapter 14, 'The interface between intellectual property rights and competition law: implications for public health in sub-Saharan Africa' by Mor Bakhoum, discusses the dual roles of competition law in relation to intellectual property laws. The author argues that competition law has roles both as an innovation instrument and as an access and dissemination tool in the context of the pharmaceutical sector. The author examines developments in intellectual property and competition law since the TRIPS Agreement, such as the increasing emphasis on intellectual property protection and commercialization since that time. Increased protection for intellectual property, as well as more aggressive application of competition law to intellectual property-related restraints to protect innovation and to enhance access and dissemination, are observable. The chapter then focuses on the interface of the two legal areas with public health, emphasizing intellectual property restrictions which affect both innovation and access, based on enforcement experience in the EU and the US and discussing reverse payment settlement cases. The author argues that competition law should, in a complementary fashion to the TRIPS Agreement, be a legal instrument fostering innovation and access in the sector. Sub-Saharan Africa is a particular focus of the discussion.

Chapter 15 by Sven Gallasch is entitled 'Pay for delay in perspective: the impact of adversarial and inquisitorial legalism on pharmaceutical antitrust enforcement'. It compares the treatment of pay-for-delay settlements in patent infringement cases and their treatment by competition authorities in the US and the EU. It asks the question: Is the EU system an imitation of the US system or is it is a more efficient version of the same process? The author examines in detail important cases on both sides of the Atlantic in the context of the contrasting legal systems. He concludes that both systems have advantages and disadvantages.

Barrister Alice Muhlebach is the author of Chapter 16, 'The Australian approach to third party infrastructure access under Part IIIA of the Competition and Consumer Act 2010'. The chapter outlines the legislative regime in place in the jurisdiction to deal with a firm that controls infrastructure which is essential to a competitor for participation in a related market. These provisions are in addition to actions for misuse of market power (abuse of dominance or monopolization), which may be available in the jurisdiction depending upon the circumstances. Recourse under the regime is not, however, dependent on a breach of competition law. The chapter briefly canvasses the treatment of this conduct in the US and the EU before focusing in depth on the Australian regime in the context of its history and operation. Using detailed case examples, the author identifies problem areas and demonstrates that the process is complex and lengthy. Despite this, a recent review of the Australian Competition and Consumer Act recommended its retention. 
Part IV of the book deals with 'Enforcement'. Chapter 17, 'The EU method of antitrust enforcement' by Andreas Stephan, sets out in detail what the author describes as 'the world's most common antitrust enforcement model'. The model is purely civil enforcement by the European Commission in a regime which is non-adversarial. Only when a party to an infringement decision appeals to the Court of Justice of the European Union is there truly independent adjudication of an issue. Penalties, however, are 'unmistakably punitive in their scale and function' and the European Court of Human Rights considers antitrust enforcement to be criminal in nature. The chapter reviews and assesses the methodology of EU antitrust enforcement in the context of hard-core cartels by focusing on the provisions of the law, the calculation of fines, and sanctions on a national level. The author concludes that there are significant shortcomings in the system, which should be addressed if the regime is to have a truly deterrent effect.

Chapter 18 by Simon Roberts is entitled 'Cartel enforcement: critical reflections from the South African experience'. The chapter details the introduction of competition law in the jurisdiction and the progress made with enforcement in cartels since that time by a relatively young regulator. The author credits several factors as contributors to enforcement success: the introduction of a corporate leniency policy (and its subsequent amendment); proactive investigation by the regulator in priority sectors; the use of settlements to identify additional offending conduct; and international cooperation, which has led to the identification of international cartels operating within the jurisdiction. The chapter discusses the distinction between hard-core cartels and other anticompetitive arrangements under the law and sets out in detail the outcomes of various cases, analysing the different reasons for this. The work also focuses on groups such as trade associations and industries, which have been more likely to undertake the conduct. Importantly, cooperation with neighbouring countries has assisted with enforcement of international cartels, as has cooperation with a wider range of jurisdictions globally. Difficulties of proof, such as showing that information exchange is a hard-core breach under the law, are also discussed. The author discusses in detail prioritization, screening and other methods used by the regulator, such as the role of settlements and leniency policy, and their impact on enforcement. These features are credited with much of the success of the regulator.

Wang Xiaoye and Adrian Emch's Chapter 19, 'Procedure and substance in China's merger control regime', explains the way in which the merger provisions of the Anti-Monopoly Law of China are applied. This is particularly significant given the importance of mergers relating to China in a global context. The chapter notes the transition from the traditional regulator, the Ministry of Commerce, following the merger of several important agencies to create the State Administration for Market Regulation. The authors note, however, that procedural divisions remain the same and mergers are still handled centrally. Comparisons with EU methodology and procedure throughout underline the distinctions between the two systems in a detailed and helpful fashion. The authors discuss in depth regulations which relate to the imposition of remedies, using case examples to clarify particular provisions. The test for mergers is said to be basically a 'substantial lessening of competition' test, similar to that of the EU, although the Anti-Monopoly Law provisions expressly mention 'public interest' as a consideration, which is an important distinction. The authors also comment on theories of harm in a merger context. They conclude that Chinese regulators have an impressive track record over their short existence. 
Part V, 'Competition policy and other issues', includes chapters on competition policy initiatives. The first two chapters deal with competition policy and the second two take a broader global view of competition law and policy.

Chapter 20, 'An effective way to keep power in an institutional cage: legislation and regulation of administrative monopoly', is written by Xu Shiying. The chapter assesses the problem of administrative monopoly, which is of substantial significance in China. She defines administrative monopoly as a combination of public power and private interests in the use of administrative power to exclude or restrict competition in the Chinese economy, issues which are not generally in competition law provisions. She outlines steps taken to redress the issue in the fairly unique provisions of the Anti-Monopoly Law of China, noting their strengths and weaknesses. The author discusses various examples of administrative monopoly and the way they have been resolved, and also addresses the Fair Competition Review System, a system for ex ante review of laws and regulations for anticompetitive features, which has been implemented to regulate administrative monopoly overall.

The second chapter addressing competition policy is Chapter 21 by Allan Fels and Wendy $\mathrm{Ng}$, 'Competition advocacy: a broader perspective'. It examines competition advocacy, which involves non-enforcement activities of competition regulators that 'promote a competitive environment, help to build a competition culture, and dissuade governments from taking actions that restrict competition'. They describe it as an essential task and in this chapter focus on advocacy as a tool to overturn government restrictions on competition, which generally create more entrenched anticompetitive impact than private conduct. They focus particularly on two dimensions which they say are overlooked in debates about competition advocacy: the political challenge in dealing with government restraints and other ways of dealing with these issues, such as laws prohibiting anticompetitive laws and regulations, constitutional provisions, and legislative reform programmes as part of broader competition policy. The authors conclude that taking a broader approach to the issue of government restrictions on competition will help to improve the effectiveness of competition advocacy by regulators.

The final two chapters deal with important global issues related to competition law and global competition generally. Chapter 22, 'Export cartels in times of populist protectionism: challenges and options for young and small competition agencies' by Pierre Horna and Leonila Papa, addresses the position of young and small competition regulators in the context of 'populist protectionist rhetoric' of larger jurisdictions and their export cartels. The authors define and discuss the operations of export cartels, their general support by governments, and their exemption from competition law. They predict that political reactions may hamper the effective enforcement of export cartels, which would damage smaller jurisdictions. The chapter outlines ways that regulators can pursue export cartels and reviews the core features of international cooperation in the area, as well as alternative solutions to address the issue.

Hassan Qaqaya has written Chapter 23, 'Complementarities and tensions between competition and trade law and policy', which rounds off the volume. The author notes that the common thread between 'free trade and competition policies is the elimination of market distortions and barriers to market entry', with the goal of promoting economic efficiency and welfare. This chapter addresses the urgent need for a comprehensive set of rules dealing with unfair practices and anticompetitive conduct in international commerce in the context of trade and competition law rules and policies.

The author underscores the difficulty with promoting market access and fair competition in the context of divergent rules for 'dealing with private market power and "behind the border" 
restraints to trade', and state-sponsored unfair trade practices. He argues that reforms are needed to accommodate competition and anti-dumping laws through either harmonization or convergence or a short-term policy stance to maintain effectiveness. He recommends a number of incremental steps to address the challenges of the difficult situation which currently exists.

In conclusion, the book addresses in detail aspects of competition law, enforcement and policy in a wide range of jurisdictions. It provides a window into developments globally and traverses the distinctions between approaches in various jurisdictions, and a range of broader issues and policy responses.

While the goals of competition law vary with economic, cultural and historic circumstances, typically it has as its central tenet protecting and increasing competition. The US and, perhaps predominantly, the EU competition laws typically form the basis for the competition law of most countries, although new adopters of competition law are more likely to add innovative features. So, too, procedures adopted for competition law enforcement vary in terms of the body responsible for enforcement - the competition authority or the court - whether penalties are punitive, and the availability of exemptions from the law. Increasingly, the methodologies adopted for assessing potentially anticompetitive conduct are converging towards effect-based tests, with the exception of cartels, which are almost universally treated as per se offences. Despite access to a range of tests and increasingly sophisticated quantitative techniques, decision errors remain a risk, with most jurisdictions opting to reduce the risk of incorrectly condemning conduct (Type 1 error) at the cost of an increased risk of failing to identify anticompetitive conduct (Type 2 error). Going forward, the digital environment raises issues such as these: How can markets be defined when products have a zero price? Is a new approach to identifying market power needed? What implications do privacy issues have for competition? All jurisdictions will be challenged when applying their competition laws to these areas. 